
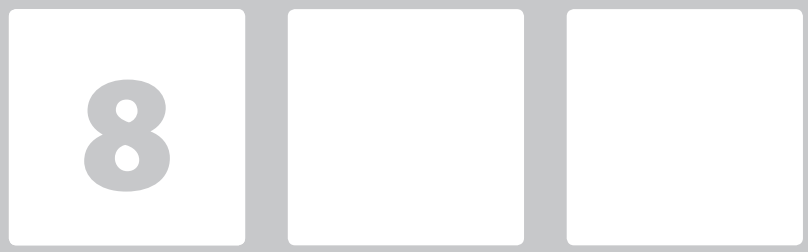

\title{
PRECARIZAÇÃO DO EMPREGO EM UM HOSPITAL PÚBLICO DE SERGIPE: UM ESTUDO DE CASO COM PROFISSIONAIS DA ENFERMAGEM
}

\section{Employment Precarization in a Public Hospital in Sergipe: \\ a case study with nursing professionals}

\section{Tereza Cecília Costa do Nascimento}

Mestre em Psicologia Social pela Universidade Federal de Sergipe. Psicóloga Organizacional do Hospital Universitário de Sergipe.

Aracaju, SE. Brasil.e-mail:tceciliacn@gmail.com

\section{Marley Rosana Melo de Araújo}

Pós-Doutorado no Programa de Pós-Graduação em Psicologia Social da Universidade Federal da Paraíba. Professora Associada II do Departamento de Psicologia da Universidade Federal de Sergipe.

Aracaju, SE. Brasil.e-mail:marleymeloaraujo@gmail.com

\section{Saulo Pereira de Almeida}

Mestre em Psicologia Social pela Universidade Federal de Sergipe. Especialista em Psicologia, Organizações e Trabalho (UNIT/Instituto Zanelli). Professor da UniAges. Aracaju, SE. Brasil. e-mail: almeidasauloalmeida@hotmail.com

\section{RESUMO}

Este trabalho investigou a percepção de precarização do emprego em um hospital público do Estado de Sergipe. O Inventário de Precarização Laboral (IPREL) foi aplicado em 279 profissionais de enfermagem e, após Análise Fatorial por Eixos Principais, rotação Promax, foram extraídos 2 fatores (Higiene Ocupacional e Justiça: $\alpha=0,87$; Relações de Trabalho: $\alpha=0,67$ ) que explicam 19,09\% da variância dos dados. Trabalhadores de enfermagem pouco vivenciam condições de trabalho adequadas e seguras e percepção de justiça nas relações estabelecidas no trabalho $(M=1,5 ; D P=0,52)$, ainda que acusem razoável ocorrência, por parte da organização empregadora, de práticas de gestão de pessoas voltadas ao reconhecimento profissional, à participação nas tomadas de decisões e à observação das obrigações trabalhistas remuneratórias ( $M=2,0 ; D P=0,51)$. Os resultados apontam para um quadro mais crítico referente às condições materiais de trabalho e relações de equidade, sinalizando a necessidade de melhorias corretivas.

Palavras-chave: Precarização do Emprego; Enfermagem; Hospital Público.

\section{ABSTRACT}

This study investigated the perception of precarious employment in a public hospital in the State of Sergipe. The Occupational Precariousness Inventory (IPREL) was applied to 279 nursing professionals and, after Main Axes Factorial Analysis, Promax Rotation, 2 factors were extracted (Occupational Hygiene and Justice: $a=0,87$, Work Relations: $a=0,67$ ) explaining $19.09 \%$ of the data variance. Nursing workers rarely experience adequate and safe working conditions and a perception of fairness in the relationships established at work $(M=1,5, S D=0,52)$, although they show a reasonable occurrence, by the employers organization, of people management practices interested in professional recognition, participation in decision-making, and the observance of labor remuneration obligations $(M=2,0, D P$ $=0,51)$. The results point to a more critical framework regarding work material conditions and equity relations, signaling the need for corrective improvements.

Keywords: Employment Precarization; Nursing; Public hospital. 


\section{INTRODUÇÃO}

O mundo do trabalho passou por diversas transformações ao longo da história que refletiram tanto na forma como o homem produz os bens que necessita para a sua sobrevivência, quanto na maneira como vive em sociedade e constrói a sua perspectiva de futuro. As diversas consequências dessas mudanças para os indivíduos são oriundas, principalmente, da organização societária decorrente da consolidação do sistema capitalista de produção e das contradições que lhes são próprias.

Especialmente nas últimas décadas, a forma de ser da classe trabalhadora sofreu grandes alterações na chamada era do capitalismo flexível (ANTUNES, 2014). Nessa fase, embora o crescimento econômico tenha se desacelerado, a lucratividade aumentou e os ganhos do capital nunca foram tão altos e tão rápidos. As transformações trazidas pela ruptura com o padrão fordista geraram outro modo de trabalho e de vida, pautado na flexibilização e na precarização do trabalho, como exigências do processo de financeirização da economia, que viabilizaram a mundialização do capital num grau nunca antes alcançado. Essa hegemonia do setor financeiro ultrapassa o terreno estritamente econômico do mercado e impregna todos os âmbitos da vida social, dando conteúdo a um novo modo de trabalho e de vida. Trata-se de uma rapidez inédita do tempo social, sustentado na volatilidade, efemeridade e descartabilidade sem limites de tudo o que se produz e, principalmente, dos que produzem - os homens e mulheres que vivem do trabalho (DRUCK, 2011). Segundo Antunes (2014), a flexibilização produtiva, as desregulamentações, as novas formas de gestão do capital, a ampliação das terceirizações e da informalidade findaram por delinear um novo contorno para o capitalismo no Brasil. A articulação complexa existente entre financeirização da economia, neoliberalismo, reestruturação produtiva e as mutações no espaço microcósmico do trabalho e da empresa não deixaram a classe trabalhadora incólume e contribuíram para uma profunda alteração nos modos de organização e nas dinâmicas do trabalho e do emprego.

A precarização do trabalho emerge nesse novo arranjo, criando uma condição de vulnerabilidade social: consiste em um processo social que modifica as condições do assalariamento (estável), anteriormente hegemônico no período da chamada sociedade salarial ou fordista, revelando-se uma tendência que atinge os indivíduos no que diz respeito à desestruturação da existência e das estruturas temporais, conferindo incerteza ao futuro e generalizando a insegurança como modo de vida (LIMA, 2010). Materializa-se, no dia a dia do trabalhador, por meio de variedade de contratos de trabalho (informais, parciais, por tempo determinado), sem proteção social e trabalhista; baixos salários; gestão organizacional que impõe metas de difícil atendimento; assédio moral; extensão da jornada de trabalho; polivalência como requisito para o desempenho das funções; terceirização $e$ quarteirização de serviços; maior exposição de fatores de risco à saúde do trabalhador; falta de investimentos em treinamento; fragilização dos sindicatos e das ações coletivas de resistência, dentre outros (ABRAMIDES; CABRAL, 2003; NAVARRO; PADILHA, 2007; PADILHA, 2009). No que concerne à saúde do trabalhador, Abramides e Cabral (2003) apontam que a precarização das relações de trabalho tem ampliado e agravado o quadro de doenças e riscos de acidentes nos ambientes ocupacionais. Para Amable, Benach e González (2001), os problemas de saúde mental que aparecem mais estreitamente associados com a insegurança do emprego são nervosismo, ansiedade, depressão, medo, sofrimento e comprometimento da sociabilidade e relações de amizade.

Conforme aquilata-se, o processo de precarização do trabalho reflete na vida do indivíduo sob os aspectos financeiro, físico, social e psíquico, constituindo uma pauta de relevância social na contemporaneidade, principalmente, porque abrange vários aspectos na sua essência. Comumente associadas aos trabalhos informais, as condições relativas à precarização também afetam as formas de emprego típicas, apesar da existência de uma legislação trabalhista que rege os contratos firmados entre empregador e empregado. Neste ponto, é importante destacar que, embora os termos emprego e trabalho sejam utilizados como sinônimos, emprego consiste numa forma específica de trabalho econômico, ou seja, pressupõe uma remuneração que é regulada por um acordo contratual (JAHODA, 1982/1987).

Observa-se que a maior parte das discussões sobre precarização gira em torno do trabalho como 
uma categoria macro que engloba as múltiplas facetas das atividades laborais, contudo este estudo enfoca nomeadamente o emprego e o indivíduo enquanto vinculado juridicamente a uma instituição que, pelas leis, reduz o trabalho a um valor de troca. Assim, deve-se considerar como emprego as formas de trabalho regularizadas, a exemplo dos contratos de trabalho por tempo indeterminado ou, até mesmo, as contratações por tempo parcial e temporárias. Excluem-se desse conjunto os trabalhos informais, autônomos ou quaisquer outras formas de trabalho em que não exista uma relação contratual estabelecida.

De acordo com Marques (2013), elementos associados à precarização, como individualização de remunerações, estímulo à competitividade e individualismo, gestão de desempenho profissional por projetos e objetivos, entre outros, também podem comparecer nos empregos típicos e contribuir para uma realidade de supercobranças, insegurança e incerteza quanto ao futuro do trabalhador na empresa. A noção de contrato por tempo indeterminado, por conseguinte, deve ser encarada com cautela, visto que a depender do conteúdo do trabalho executado - se é pobre e desqualificado -, há uma maior propensão à condição de desemprego e ao sentimento de insegurança por parte do trabalhador. Tal situação potencializa-se na atualidade, na medida em que a conjuntura socioeconômica rareia as colocações formais e multiplica um contingente de mão-de-obra reserva ávido por uma oportunidade profissional.

Amable, Benach e González (2001) estudaram especificamente a precariedade do emprego, definindo-a como um constructo multidimensional que compreende características contratuais de emprego precário (instabilidade no emprego, negociação individual sobre as condições de trabalho, baixos salários e falta de condições econômicas, direitos e proteção social limitados no local de trabalho), além de dimensões sociais peculiares a relações laborais precárias (autoritarismo das chefias e direitos trabalhistas comprometidos). Entende-se, por todas as questões elucidadas, que a identificação com acurácia dos empregos precarizados torna-se um empreendimento importante na atualidade para que, assim, seja viável a compreensão e definição de estratégias adequadas para o combate de situações que prejudiquem o homem na sua forma de existir no ambiente laboral.
Estudos dessa natureza são escassos na literatura, em parte pela carência de instrumentos estruturados que examinem a ocorrência e intensidade da precarização do emprego.

Segundo Elias e Navarro (2006), o hospital é reconhecidamente um espaço laboral insalubre, penoso e perigoso para os seus trabalhadores, com potencialidade para constituir-se em um ambiente de precarização. Caracteriza-se por ser um local propício ao adoecimento, pois, além dos riscos de acidentes e doenças de ordem física aos quais os profissionais estão expostos, o sofrimento psíquico é também comum e parece estar em ascensão diante das transformações sucedidas no mundo do trabalho nos últimos anos, uma vez que a intensificação laboral é traço típico da atual fase do capitalismo, e trouxe consigo a insegurança gerada pelo medo do desemprego, que faz com que as pessoas sucumbam a regimes e contratos de trabalho precários, percebendo baixos salários em condições de trabalho, geralmente, indignas.

Como toda organização, o ambiente hospitalar reproduz as características do contexto sócio histórico em que está inserido, sendo que a incorporação de novas tecnologias não trouxe para o trabalhador dos hospitais alívio na sua carga de trabalho. As atividades dos profissionais de saúde são marcadas por forte tensão, devido às extensas jornadas de trabalho, ao número restrito de trabalhadores e ao desgaste psicoemocional a que estão expostos. Ademais, a necessidade de funcionamento diuturno, que implica na existência de regime de turnos e plantões, tolera a ocorrência de mais de um emprego, situação corriqueira na área da saúde, em que os profissionais mantêm mais de um vínculo empregatício, visando a complementação da renda familiar (ELIAS; NAVARRO, 2006).

Escolheu-se como campo de estudo para a realização desta pesquisa o Hospital de Urgências de Sergipe (HUSE), uma vez que esta instituição pública forma um sistema organizacional vasto, dinâmico, complexo e que cumpre um relevante papel na prestação de serviços de saúde à população local. O quadro funcional é composto por, aproximadamente, 3,2 mil funcionários, dos quais 1.722 são estatutários e 1.512, celetistas contratados por meio de concurso público. 
O hospital em questão foi implantado no ano de 1986 e representa a principal porta de entrada do Sistema Único de Saúde (SUS) para os casos de alta complexidade no Estado de Sergipe. Atende em torno de 15 mil pacientes por mês. Além de ser titular da maior urgência e emergência, e ser referência no tratamento de câncer em nível estadual, sua estrutura possui, dentre outros, uma Unidade de Tratamento Intensivo e Semi-Intensivo Adulto, Central de Tratamento Intensivo Pediátrica (CTI-PED), Centro Cirúrgico com nove salas cirúrgicas e uma Sala de Recuperação Pós-Anestésico (SRPA) e dispõe da única Unidade de Tratamento de Queimados (UTQ) do Estado.

Segundo Hora, Ferreira e Silva (2013), dentre as profissões mais afetadas pelo estresse, estão as relacionadas com a saúde, como médicos, enfermeiros, fisioterapeutas, psicólogos, nutricionistas. A presente pesquisa restringiu a investigação da percepção de precarização do emprego entre enfermeiros, auxiliares e técnicos de enfermagem, que constituem o maior grupo de trabalhadores nos hospitais. Para Belancieri, Beluci, Silva e Gasparelo (2010), a equipe de enfermagem é responsável por $60 \%$ das ações de saúde, prestando assistência 24 horas por dia à população, sendo a categoria que mais contato tem com o ambiente de saúde e com os doentes, numa atmosfera de dor e aflição que, geralmente, emerge nesse contexto. Dentre as atividades desenvolvidas constatam-se ações de promoção, proteção e recuperação da saúde, assistindo o ser humano através de um processo de trabalho específico, que envolve a avaliação das condições de saúde, a prescrição e implementação de cuidados e a reavaliação contínua de todo esse processo (SOUZA et al., 2010).

Face ao exposto, evidencia-se que se trata de um labor que demanda esforço emocional constante para o enfrentamento de uma rotina de pressão em que o trabalho precisa ser compreendido observando-se os elementos psicossociais existentes em seu bojo. A equipe de enfermagem assume um importante papel na dinâmica hospitalar, interagindo tanto com os distintos profissionais que fazem parte do corpo técnico administrativo e de saúde, como com os pacientes e seus acompanhantes em espaços laborais que, em sua maioria, são insalubres e não oferecem condições apropriadas ao bem-estar dos trabalhadores. Seu trabalho apresenta cargas excessivas, físicas e mentais, acúmulo de horas trabalhadas, deficiência de material, má remuneração, vínculos empregatícios que trazem instabilidade (SOUZA et al., 2010), aspectos que endossam a precarização do trabalho. Por essa razão, percebe-se na literatura nacional alguns esforços de compreensão da precarização do trabalho e os seus impactos junto aos profissionais de enfermagem, a exemplo de Fontana e Lautert (2013) e Silva e Muniz (2011). Entretanto, as pesquisas identificadas possuem um viés eminentemente qualitativo, o que justificaria a importância da investigação da percepção do processo de precarização com um enfoque metodológico quantitativo, apresentando, assim, um novo olhar sobre a matéria, alargando a sua compreensão e desvendando novos caminhos para um enfrentamento responsável das situações enfrentadas por esses trabalhadores, fundamentais no sistema de saúde (BACKES et al., 2012).

Dessa forma, este estudo teve como intuito principal identificar a percepção de precarização do emprego junto aos profissionais da enfermagem do HUSE. Especificamente, objetivou-se: a) verificar a magnitude e preponderância das dimensões da precarização do emprego para este público-alvo; b) investigar a relação entre variáveis sociodemográficas, laborais e precarização do emprego; c) realizar nova validação da medida Inventário de Precarização Laboral (IPREL) com a amostra de profissionais em tela.

\section{MÉTODO}

\subsection{Participantes e local do estudo}

A amostra deste estudo foi composta por 279 profissionais de enfermagem do HUSE, os quais estavam há, pelo menos, seis meses em atividade na instituição, distribuídos entre os cargos de enfermeiro $(17,2 \%)$, técnicos em enfermagem $(69,5 \%)$ e auxiliares e assistentes de enfermagem (13,3\%). O cálculo amostral utilizou como referencial a quantidade mínima de 5 participantes por cada item constituinte do instrumento de pesquisa (PASQUALI, 2012), o que totalizava um número mínimo necessário de 250 pessoas. 
Do total de participantes deste estudo, $86,7 \%$ $(\mathrm{n}=242)$ são do sexo feminino e $13,3 \%(\mathrm{n}=37)$ do sexo masculino. Verificou-se grande variabilidade de idades, desde 23 até 68 anos $(\mathrm{M}=36,7 ; \mathrm{DP}=7,37)$. No que diz respeito à escolaridade, $48,0 \%$ possuía ensino médio completo, $23,3 \%$ com nível superior incompleto e $28,7 \%$ apontou nível superior completo ou acima. O tempo médio de trabalho na empresa correspondeu há 7,5 anos ( $\mathrm{DP}=4,5)$, com alta variabilidade entre os participantes (de 8 meses a 20 anos e 6 meses). Quanto ao tipo de vínculo empregatício com a instituição pesquisada, $88,5 \%$ era do quadro efetivo e $11,5 \%$, terceirizados. O salário e a carga horária trabalhada por semana eram, respectivamente: a) Salário: $\mathrm{M}=\mathrm{R} \$ 1.382,18$ (DP = R \$ 616,97), variando de $\mathrm{R} \$ 784,00$ a $\mathrm{R} \$ 3.100,00$; b) Carga horária: $\mathrm{M}=$ $36,33(\mathrm{DP}=8,67)$, variando de 12 a 78 horas.

\subsection{Instrumentos}

Foi empregado um questionário para a obtenção dos dados sociodemográficos (sexo, idade, estado civil, quantidade de filhos, escolaridade) e laborais (vínculo com a empresa, cargo, tempo de trabalho na empresa, tempo de trabalho no cargo, carga horária semanal, salário, vínculo da categoria com o sindicato, benefícios recebidos e percepção acerca do salário). Para aferir a percepção de precarização do emprego, utilizou-se o Inventário de Precarização Laboral (IPREL), desenvolvido por Araújo, Jesus e Rodrigues (2017, no prelo). O referido instrumento é autoaplicável e intenciona medir o grau de precarização vivenciado pelo trabalhador que possui vínculo empregatício. Trata-se da primeira medida dessa natureza concebida no Brasil, intencionando suprir uma carência metodológica detectada na literatura, a fim de melhor mapear a precarização e relacioná-la aos seus prováveis efeitos deletérios na vida do trabalhador.

O IPREL é composto por 50 itens, dispostos em escala Likert de 4 pontos, variando desde (0) não se aplica até (3) aplica-se totalmente, na qual o indivíduo aponta em que medida as situações descritas correspondem ao que acontece em seu ambiente de trabalho.
Essa escala gerou dois fatores em seu processo de validação fatorial com amostra geral de trabalhadores (ARAÚJO; JESUS; RODRIGUES, 2017, no prelo):

F1 - Suporte organizacional - insuficiente ou inexistente, na forma de adequadas condições de trabalho e de administração de processos produtivos voltados a garantir a plena execução das atividades de trabalho e 0 alcance de efetivos desempenhos pelos trabalhadores (29 itens; $\mathrm{r}^{2}=18,62 ; \alpha=0,92$ );

F2 - Exploração e sofrimento - ambiente em que o trabalhador é exigido mais do que suas condições permitem (condições físicas, psicológicas, legais) e práticas laborais que podem degradar a vida do trabalhador ou sua integridade psicológica (21 itens; $r^{2}=6,52 ; \alpha=0,87$ ).

Embora o instrumento tenha apresentado, através das técnicas estatísticas utilizadas (Análise Fatorial Exploratória - AFE, Análise Paralela e Coeficiente Alpha de Cronbach), resultados indicativos de qualidades psicométricas capazes de cumprir a meta de traduzir o que seja precarização do emprego e de preencher a lacuna metodológica verificada na área, os autores da escala (ARAÚJO; JESUS; RODRIGUES, 2017) recomendaram a aplicação do IPREL em novas amostras brasileiras, com o intuito de atestar suas propriedades e confirmar a sua estrutura fatorial interna. Destarte, a amostra do presente estudo consiste num público ocupacional específico, profissionais da enfermagem vinculados a uma mesma instituição empregadora e expostos a um mesmo contexto cultural de trabalho, fato que pode influenciar a percepção de precarização laboral.

\subsection{Procedimentos de coleta de dados e aspectos éticos}

Inicialmente, buscou-se a autorização do HUSE, através do seu Núcleo de Educação Permanente NEP, para a realização da pesquisa (liberação dos profissionais para a participação na pesquisa e do espaço físico para aplicação dos instrumentos).

Uma vez obtida a autorização, seguiu-se a aplicação dos questionários de forma presencial no ambiente hospitalar, conforme as considerações éticas para pesquisas com seres humanos da Resolução CNS 466/12. A coleta de dados contou com a parti- 
cipação de uma equipe de 4 assistentes de pesquisa (estudantes do curso de enfermagem) como uma estratégia de abordagem da população do estudo em diferentes turnos de trabalho e como forma de abreviar o tempo de coleta de dados. Todos os instrumentos utilizados foram impressos e entregues aos participantes da pesquisa de forma individual e/ ou coletiva, sem imposição de tempo limite de resposta para preenchimento dos formulários. Somente participaram aqueles que preencheram o Termo de Consentimento Livre e Esclarecido.

As instruções foram lidas pelos pesquisadores, quando da aplicação do questionário, os quais ficavam à disposição para dirimir eventuais dúvidas dos participantes, antes e durante o preenchimento do material. Os participantes eram informados acerca de aspectos de sua participação, tais como anonimato, sigilo dos dados, liberdade de resposta e de desistência da atividade, riscos e benefícios associados. Esta pesquisa foi aprovada pelo Comitê de Ética em Pesquisa com Seres Humanos do Hospital Universitário de Sergipe (CEP-HU/UFS) sob o registro CAAE no 41093315.9.0000.5546.

\subsection{Análise de dados}

Para a análise dos dados utilizou-se o programa estatístico SPSS (Statistical Package for the Social Sciences), versão 19.0. Inicialmente, procedeu-se o exame do banco de dados quanto a erros de digitação, dados faltosos ou casos extremos. Em seguida, foram realizadas estatísticas descritivas (medidas de tendência central, dispersão e frequência) para caracterização da amostra, finalizando com a realização da Análise Fatorial Exploratória e extração dos coeficientes Alpha de Cronbach, que consiste no indicador que estima a confiabilidade de um instrumento, além de verificação dos escores médios da amostra nos fatores. Adicionalmente, foram realizadas análises bivariadas (correlação de Pearson, teste $t$ de Student e teste $U$ de Mann-Whitney, análise de variância e ANOVA Kruskal-Wallis) para averiguação de associações significativas entre as variáveis sociodemográficas e laborais e as dimensões da precarização do emprego.

\section{RESULTADOS E DISCUSSÃO}

A presente seção está estruturada em duas partes. Primeiramente, aborda-se os resultados provenientes da investigação de validade e confiabilidade do instrumento e, em seguida, os resultados das análises bivariadas realizadas.

\subsection{Análise fatorial exploratória (AFE)}

A AFE tem como fundamento a redução de uma certa quantidade de itens a um número menor de variáveis, podendo ser conceituada como um conjunto de técnicas multivariadas que possibilita encontrar a estrutura subjacente em uma matriz de dados e definir o número e a natureza das variáveis latentes que representam, de forma mais adequada, um conjunto de variáveis observadas (DAMÁSIO, 2012).

Antes de ser realizada a AFE propriamente dita, deve ser apurado se a matriz de dados é passível de fatoração. Assim, foram utilizados dois métodos para a avaliação desse pressuposto, os quais tendem a ser uniformes: o critério de Kaiser-Meyer-Olkin (KMO) e o Teste de Esfericidade de Bartlett. O teste de adequação da amostra resultou em $\mathrm{KMO}=0,79$, o qual em conjunto com o Teste de Esfericidade de Barlett, $\left(\chi_{(122)}^{2}=4258,75 ; \mathrm{p}<0,001\right)$, comprovaram a fatorabilidade do IPREL.

Superadas essas análises, prosseguiu-se para o exame do número de fatores a serem retidos. A solicitação de solução inicial, por meio de extração dos Componentes Principais (Principal Component Analysis - PC), apontou a possibilidade de retenção de até 14 componentes pelo critério de eingenvalue $>1$, contabilizando 59,76\% de variância explicada, ainda que apenas seis fatores atendessem ao critério de Harman (1967), o qual exige que cada fator não encerre menos do que 3\% de variância dos dados. Quanto ao gráfico Scree Plot (Figura 1), este sinalizava a existência de três fatores, aparentemente distintos. Como a análise isolada dos critérios supramencionados pode induzir a erros que comprometam a interpretação dos resultados, quais sejam, retenção de um número de fatores maior que o adequado ou subestimação 
da quantidade de fatores, combinou-se a análise dos critérios e a relevância teórica das soluções fatoriais para a imputação do número de fatores.

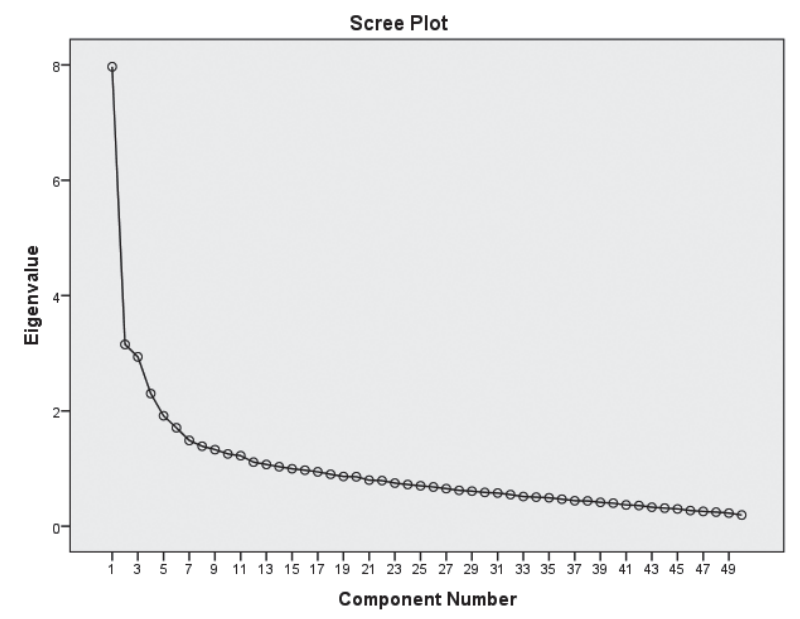

Figura 1 Gráfico Scree Plot

Fonte: Dos autores.
A partir disso, foram realizadas extrações para buscar a melhor disposição de itens por fator, tanto estatisticamente quanto conceitualmente. Investigou-se a possibilidade de várias soluções fatoriais utilizando extração por Componentes Principais (Principal Component Analysis - PC) e por eixos principais (Principal Axis Factoring - PAF), rotações ortogonais e oblíquas, carga fatorial 0,30 para manutenção do item, desde solicitação de cinco até dois fatores. Tais soluções, em geral, apresentavam problemas de dubiedade de interpretação dos fatores resultantes. Por fim, optou-se pela solução mais parcimoniosa e de melhor interpretabilidade, alcançada por meio de extração PAF, rotação fatorial oblíqua do tipo Promax com carga fatorial 0,30 e estipulação de dois fatores $\left(r^{2}=19,09 \%\right)$. Permaneceram 38 itens na escala $(\alpha$ $=0,85)$, os quais ficaram distribuídos nos fatores de acordo com a Tabela 1.

Tabela 1 Estrutura interna do Inventário de Precarização Laboral (IPREL), encontrada com o estudo atual

\begin{tabular}{|c|c|c|c|c|c|c|c|}
\hline Nome & Definição & No de itens & $\mathbf{r}^{2}$ & $\begin{array}{c}\text { Eingen } \\
\text { value }\end{array}$ & $a$ & $M$ & DP \\
\hline $\begin{array}{l}\text { F1 - } \\
\text { Higiene } \\
\text { Ocupacional e } \\
\text { Justiça (HO \& J) }\end{array}$ & $\begin{array}{l}\text { Refere-se aos aspectos da situação labo- } \\
\text { ral relacionados com segurança/saúde } \\
\text { do trabalhador e com a percepção de } \\
\text { justiça nas trocas existentes na díade } \\
\text { empregador/empregado. }\end{array}$ & $\begin{array}{c}26 \\
(-30 ;-44 ; 12 ; 39 ;-16 ; \\
-18 ;-35 ; 25 ; 23 ; 37 \\
-20 ;-32 ; 45 ;-27 ; 46 ; \\
49 ; 10 ;-02 ; 15 ; 8 ;-43 ; \\
\quad 19 ; 7 ;-01 ; 29 ; 34)\end{array}$ & 14,4 & 7,21 & 0,87 & 1,5 & 0,52 \\
\hline $\begin{array}{l}\text { F2 - } \\
\text { Relações de } \\
\text { Trabalho (RT) }\end{array}$ & $\begin{array}{l}\text { Trata de questões atreladas à gestão de } \\
\text { pessoas e às responsabilidades patronais } \\
\text { na relação trabalhista }\end{array}$ & $\begin{array}{c}12 \\
(40 ; 47 ;-36 ; 41 ; 50 \\
-21 ; 42 ;-14 ; 11 ; 33 \\
48 ;-38)\end{array}$ & 4,67 & 2,34 & 0,67 & 2,0 & 0,51 \\
\hline
\end{tabular}

Fonte: Dos autores.

De forma análoga ao modelo proposto por Araújo, Jesus e Rodrigues (2017, no prelo), foram encontrados dois fatores, contudo eles foram alternativamente denominados de Higiene Ocupacional e Justiça (HO \& J) e Relações de Trabalho (RT), uma vez que se constatou que ocorreu uma reorganização dos itens nos fatores, legitimando a necessidade de uma nova interpretação para as duas dimensões identificadas. Deve-se pontuar que tal situação pode ser consequência do fato de que a amostra (287 trabalhadores) utilizada na pesquisa original de validação do IPREL era variada, combinada por pessoas de diversas profissões e cargos em distintas empresas (ARAÚJO; JESUS; RODRIGUES, 2017, no prelo), enquanto que no presente estudo obteve-se um grupo homogêneo de trabalhadores de única categoria, oriundos de um espaço laboral comum, o que pode contribuir para uma particularização da ideia do que seja precarização do emprego.

Verifica-se, a partir dos dados, que o fator 1 (HO \& J) apresentou bom nível de consistência interna ( $\alpha$ $=0,87)$ e que o fator $2(\mathrm{RT})$ exibiu um alfa abaixo do mínimo de 0,70, considerado aceitável (GEORGE; MALLERY, 2003), porém ainda próximo $(\alpha=0,67)$. 
Cumpre ressaltar que, em virtude deste estudo não ter como escopo o teste do modelo explicativo para precarização do emprego, não se teve a pretensão de realizar análise fatorial confirmatória. Dessa forma, os resultados desta pesquisa disponibilizam uma alternativa de estrutura fatorial para o IPREL, embora sejam necessárias amostras adicionais e análises confirmatórias para decidir a estrutura que proporcione uma melhor compreensão sobre a precarização do emprego percebida pelo trabalhador.

Antes de prosseguir, é válido reforçar que o IPREL tem a aspiração de aferir o que seja um emprego precário, ou seja, busca compreender o que isso significa para a amostra ora pesquisada. Partindo da observação dos itens que carregaram com destaque em cada fator, tais como: F1 - itens 30 e 44 - "o ritmo de trabalho é excessivo" (invertido) e "o trabalhador exerce mais atividades do que aquelas previstas para seu cargo" (invertido); F2 - itens 40 e 47 - "o trabalho coordenado pelas chefias é feito de maneira justa" e "a empresa ajuda o trabalhador quando acontece algum acidente de trabalho", pode-se apreender que, para os participantes, emprego precarizado é aquele em que o trabalhador se percebe injustiçado pelas práticas de gestão vivenciadas, sobrecarregado no exercício das suas atividades, sem condições de exercê-las com segurança, prejudicando o seu bem-estar físico e mental.

Quanto aos escores da amostra em cada fator, os valores médios denotam que os trabalhadores pesquisados vivenciam pouco $(\mathrm{M}=1,5 ; \mathrm{DP}=0,52)$ os aspectos de Higiene Ocupacional e Justiça (HO \& $\mathrm{J})$ no hospital pesquisado, ainda que acusem como razoável $(\mathrm{M}=2,0 ; \mathrm{DP}=0,51)$ a vivência dos aspectos relativos a Relações de Trabalho (RT). Verificou-se, por meio da distribuição de frequência de respostas para cada fator, que $54,5 \%$ dos participantes está localizada em intervalo de respostas entre 1,5 ou menos para o fator $\mathrm{HO} \& \mathrm{~J}$, e que $50,5 \%$ possuem pontuações inferiores até 2,0 na escala do fator RT.

$\mathrm{O}$ fator $\mathrm{HO} \& \mathrm{~J}$ abrange aspectos relacionados ao oferecimento, por parte da instituição, de condições de trabalho adequadas e seguras que asseverem a saúde e o bem-estar do colaborador no exercício de suas atividades, bem como contempla a percepção de justiça nas trocas existentes na díade empregador/ empregado. Já o fator RT contempla ideias associadas à gestão de pessoas e às responsabilidades patronais na relação trabalhista como: reconhecimento profissional, participação nas tomadas de decisões, respeito aos empregados como seres humanos, atendimento a legislação trabalhista quanto a pagamento de salários, benefícios e filiação ao sindicato. Os escores encontrados quanto à percepção de precarização do emprego apontam para um quadro mais crítico no que tange às condições materiais de trabalho e relações de equidade, ainda que também não tenha sido satisfatório o indicador que versa sobre as práticas e políticas de gestão de pessoas.

O dado encontrado nesta pesquisa quanto à baixa percepção por parte dos profissionais de aspectos de HO \& J foi ilustrado por Souza et al. (2010) em um estudo que investigou enfermeiros de um hospital universitário do Rio de Janeiro que, em uma conjuntura de precarização das condições de trabalho, necessitavam fazer adaptações nos insumos hospitalares para garantirem o oferecimento do cuidado, pois os materiais e equipamentos necessários para os atendimentos eram insuficientes, inexistentes e/ou a qualidade era inadequada para o fim a que se destinavam. Para os autores, a precariedade das condições de trabalho fazia com que o enfermeiro apresentasse mais sofrimento que prazer durante a realização de suas atividades laborais, na medida que tinha que prover a ausência de insumos através da adaptação e improvisação de materiais e equipamentos, gerando frustração, irritabilidade, raiva, medo e impotência.

\subsection{Análises bivariadas}

Com o objetivo de averiguar como os fatores do IPREL se associavam significativamente às variáveis sociodemográficas (sexo, idade, escolaridade) e laborais (vínculo com a empresa, cargo, tempo de trabalho na empresa, tempo de trabalho no cargo, carga horária semanal, salário e percepção acerca do salário), foram utilizados os seguintes testes: correlação de Pearson, análise de variância, ANOVA Kruskall-Wallis, teste $t$ de Student e teste $U$ de Mann-Whitney.

Verificou-se, através de correlações de Pearson, relações positivas e significativas entre o fator Higiene Ocupacional e Justiça e os aspectos dos vencimentos percebidos pela amostra pesquisada: o salário atual cobre as necessidades básicas $(\mathrm{r}=0,29 ; \mathrm{p}<0,001)$ e 
o salário atual cobre despesas imprevistas $(\mathrm{r}=0,31$; $\mathrm{p}<0,001)$. Quanto menos as pessoas acreditam que o salário dê conta de cobrir as suas despesas básicas, assim como aquelas imprevistas, menos percebem que a organização mantenha uma relação de justiça com seus colaboradores. Em diversos estudos da área de enfermagem, nota-se que a categoria considera a remuneração recebida como fonte de insatisfação no exercício da profissão (LIMA; PEDRÃO; GONÇALVES; LUIS, 2010; RODRIGUES et al., 2014; SCHMIDT; DANTAS, 2006). De acordo com Chiavenato (2004), a remuneração (salário e benefícios) é a retribuição dada ao funcionário de acordo com o trabalho, dedicação e esforço pessoal desenvolvido por ele, através de seus conhecimentos e habilidades, permitindo ao trabalhador a aquisição de bens que garantam a sua subsistência e o seu bem-estar social. Fundamentados nessa noção, o indivíduo deve perceber como equânime a contrapartida oferecida pela instituição ao seu esforço despendido mensalmente. Dentre os profissionais deste estudo, a percepção de que o salário não consegue cumprir as necessidades básicas, nem as despesas imprevistas, resvala na baixa percepção dos elementos de higiene ocupacional e justiça, mormente porque o pagamento pelos serviços prestados é uma recompensa que deve ser percebida como justa e deve conferir segurança ao trabalhador para que supra as suas necessidades de subsistência. Nessa perspectiva, deve-se atentar para os riscos da percepção de inequidade produzir o fenômeno de injustiça organizacional, o qual tem demonstrado poder heurístico para a compreensão de atitudes e comportamentos organizacionais, dentre eles a retaliação organizacional (MENDONÇA; TAMAYO, 2004).

O teste $U$ foi utilizado para verificar a existência de diferença significativa entre sexos masculino e feminino, e entre vínculo empregatício efetivo e terceirizado no que tange aos escores nos fatores identificados (HO \& J e RT). Primeiramente quanto ao sexo, encontrou-se relação com o fator Relações de Trabalho ( $U=3430,5 ; z=-2,29 ; p=0,022)$, denotando que participantes do sexo masculino (mediana $=1,83$ ) tendem a perceber mais negativamente que as mulheres (mediana $=2,08$ ) os aspectos encerrados no fator Relações de Trabalho. Conforme elucidado anteriormente, o fator RT contempla ideias associadas à gestão de pessoas e às responsabilidades patronais na relação trabalhista, assim, o fato dos profissionais do sexo masculino experimentarem de forma mais desfavorável que as mulheres aspectos atinentes a RT nesta pesquisa é curioso, já que os estudos apontam que a vivência de precarização se encontra mais disseminada nos grupos compostos por mulheres, jovens, negros e os mais velhos (CADONÁ; GÓES, 2013; HIRATA, 2009). Entretanto, é importante mencionar que a feminilização é uma característica forte das equipes que oferecem assistência à saúde, ou seja, a maioria é feminina, representando atualmente mais de $70 \%$ de todo o contingente. No caso das equipes de enfermagem, esse processo de feminilização ultrapassa 90\% (MACHADO; VIEIRA; OLIVEIRA, 2012). Assim, apesar dos dados evidenciarem que há uma presença crescente do contingente masculino na enfermagem, esse grupo é minoritário na categoria estudada, porém tem anseios diferenciados quanto às perspectivas profissionais. Segundo Skevington e Dawkes (1988), existe uma expectativa muito maior em relação à mobilidade ascendente na carreira por parte dos homens (100\% comparativamente com 53\% das mulheres), os quais também se incomodam mais com o baixo estatuto da profissão de enfermagem que as mulheres.

Já no tocante à comparação entre o tipo de vínculo empregatício e os dois fatores da escala, verifica-se diferença significativa entre terceirizados e efetivos em ambos os fatores: $\mathrm{HO} \& \mathrm{~J}(\mathrm{U}=2726,00$; $\mathrm{z}=-2,86 ; \mathrm{p}=0,004)$ e RT $(\mathrm{U}=2267,00 ; \mathrm{z}=-3,93 ; \mathrm{p}$ $<0,001)$. Os participantes terceirizados apresentaram maior escore em Relações de Trabalho (mediana = 2,42 ) em comparação aos efetivos (mediana $=2,0$ ), ou seja, aqueles que possuem vínculo direto de prestação de serviço com o hospital e, no caso, como se trata de uma instituição pública, com o Estado. Esse resultado reflete uma insatisfação dos efetivos quanto aos aspectos das relações de trabalho. Embora se conheça as dificuldades dos terceirizados na conquista de melhorias, como salários e benefícios, em função da legislação trabalhista que lhes é pertinente e da natureza precarizada do seu vínculo empregatício, o fator RT remete, para além de questões de atendimento aos pressupostos legais, à gestão de pessoas. Nesse ponto, Filippim e Gemelli (2010) destacam que a gestão de pessoas na esfera pública necessita 
implantar um sistema de incentivos mais eficaz para o profissional, pois faltam políticas continuadas e efetivas de formação, capacitação e remuneração coerente com o exercício da função pública.

No que concerne ao fator Higiene Ocupacional e Justiça, observa-se que os funcionários terceirizados (mediana $=1,27$ ) apreendem este fator de forma mais desfavorável que os efetivos (mediana $=1,50$ ). Neste ponto, Lima (2010) observa que a terceirização, além de ter acarretado transformações do ponto de vista da estratégia empresarial gerou, também, mudanças com impactos significativos em direção à maior precarização das condições e relações de trabalho, afetando os trabalhadores em sua organização coletiva e planejamento da vida pessoal e familiar. Ademais, no que diz respeito à remuneração, a convivência de múltiplos vínculos empregatícios em um mesmo espaço laboral é terreno fértil para o surgimento de sentimentos de iniquidade por parte do trabalhador terceirizado, uma vez que, muitas vezes, desempenham funções semelhantes aos dos profissionais efetivos e recebem uma remuneração inferior, criando um sistema de iniquidade dentro de um mesmo espaço laboral. Estudos com trabalhadores terceirizados da Petrobrás e indústrias petroquímicas na Bahia assinalam para um tratamento diferenciado dos trabalhadores dentro das plantas industriais, evidenciando uma diferenciação entre os "de fora" e os "de dentro" - que ainda permanecem como funcionários da empresa. Condições de trabalho degradantes, falta de equipamento adequado, refeitórios diferenciados, portarias, vestiários, banheiros, uniformes e outras marcas de diferenciação compõem o dia a dia desses trabalhadores (LIMA, 2010).

Outro teste utilizado foi a análise de variância para a comparação dos níveis de escolaridade com os dois fatores da escala. Concluiu-se que existem diferenças significativas entre os níveis de escolaridade no que tange aos escores nos fatores $\left(\mathrm{F}_{(2,276)}=5,92 ; \mathrm{p}=\right.$ $0,003)$. Pessoas que detêm nível superior incompleto são as que mais percebem a precarização $(M=1,27$; $\mathrm{DP}=0,47$ ) do ponto de vista da Higiene Ocupacional e Justiça em relação aos participantes com outros níveis de escolaridade. Esse resultado coaduna com o argumento de que a precarização se estende para o conjunto da sociedade e passa a atingir até mesmo indivíduos cujas posições e profissões eram consi- deradas, em outros tempos, seguras (RAMALHO; SANTANA, 2003), atingindo profissionais de nível superior que passam a se perceber em um contexto de incertezas, em que o grau de escolaridade não é mais garantia de um emprego estável, inclusive nos países ditos desenvolvidos (MÉSZÁROS, 2006).

O outro cruzamento utilizou o teste ANOVA Kruskall-Wallis relacionando o cargo aos fatores, e encontrando diferença significativa entre os três grupos de cargos pesquisados e o fator Higiene Ocupacional e Justiça $\left(\mathrm{X}_{(2)}^{2}=6,12 ; \mathrm{p}=0,047\right)$ : Enfermeiro (mediana $=1,69$ ), técnico em enfermagem (mediana $=1,39$ ) e outros (mediana $=1,46)$. Nesse ponto, deve-se elucidar que os profissionais que desempenham o cargo de nível técnico vivenciam menos frequentemente os aspectos atinentes à $\mathrm{HO} \& \mathrm{~J}$ que os demais cargos pesquisados e compreendem não somente a maior parte dos participantes desta pesquisa, como de todo o corpo de enfermagem. São esses profissionais que executam as tarefas de auxílio ao enfermeiro e de assistência integral aos pacientes, especialmente aos que apresentam quadro clínico grave, de alto risco.

\section{CONSIDERAÇÕES FINAIS}

O objetivo central deste trabalho consistiu em identificar a percepção de precarização do emprego junto aos profissionais da enfermagem do HUSE. Para tanto, foi necessário realizar nova validação da medida Inventário de Precarização Laboral (IPREL), identificar a magnitude e preponderância das dimensões da precarização do emprego para este público-alvo e investigar a relação entre variáveis sociodemográficas, laborais e a precarização do emprego.

Quanto ao IPREL, este apresentou índices de confiabilidade adequados e mostra-se uma medida válida para aferir a percepção de precarização do emprego. A partir desta pesquisa, obteve-se uma escala mais enxuta que passou a ter 38 itens dos 50 propostos inicialmente. As dimensões encontradas, Higiene Ocupacional e Justiça e Relações do Trabalho, corroboram aspectos centrais associados à precarização do emprego encontrados na literatura, embora divirjam daquelas apontadas inicialmente pelos autores da escala. Assim, tem-se uma medida atualizada e abrangente do ponto de vista da análise das condições 
do ambiente de trabalho que poderá ser utilizada em diferentes estudos. Recomenda-se que o instrumento seja aplicado em outras amostras e seja submetido a testes mais sofisticados, tais como Análise Fatorial Confirmatória, para verificar se a estrutura fatorial se mantém, assim como considera-se relevante que sejam empreendidos estudos para verificar a relação de percepção de precarização com outros constructos.

Os valores médios encontrados através da aplicação do IPREL, demonstram que os trabalhadores de enfermagem vivenciam pouco os aspectos de Higiene Ocupacional e Justiça no hospital pesquisado, ainda que acusem como razoável a vivência dos aspectos relativos à Relações de Trabalho, o que endossa a necessidade de intervenções junto a este público para minimizar/reverter o diagnóstico identificado. A equipe de enfermagem tem uma atuação crucial, revestida de significados na promoção da saúde, uma vez que o trabalho realizado é mediado pela interação e comunicação entre profissionais e paciente, constituindo-se em processo humano, essencialmente intersubjetivo. Nesse sentido, conforme asseveram Wisniewski, Silva, Évora e Matsuda (2015), o trabalho deve ser analisado em termos dos elementos que o constituem, pois a satisfação e a insatisfação para com o mesmo denota o resultado da interação entre o ambiente, o trabalhador e os elementos laborais.

Como limitação deste estudo, deve-se mencionar que a amostra utilizada foi não probabilística e por conveniência, sem representatividade populacional, por essa razão, é preciso cautela quanto à generalização dos resultados. Como sugestão para pesquisas futuras sobre o tema, recomenda-se a realização de estudos de caráter correlacional, associando a precarização do emprego a outras variáveis do comportamento individual e/ou organizacional, a exemplo da saúde mental dos trabalhadores.

\section{REFERÊNCIAS}

ABRAMIDES, M. B. C.; CABRAL, M. S. R. Regime de acumulação flexível e saúde do trabalhador. São Paulo em Perspectiva, v. 17, n. 1, p. 3-10, 2003.
AMABLE, M.; BENACH, J.; GONZÁLEZ, S. La precariedad laboral y su repercusión sobre la salud: conceptos y resultados preliminares de un estudio multimétodos. Archievos de Prevención de Riesgos laborales, v. 4, n. 4, p. 169-184, 2001.

ANTUNES, R. Desenhando a nova morfologia do trabalho no Brasil. Estudos Avançados, v. 28, n. 81, p. 39-53, 2014.

ARAÚJO, M. R. M.; JESUS, R. M.; RODRIGUES, H. S. Concepção e validação do Inventário de Precarização Laboral. Psicologia: Organizações e Trabalho, 2017, no prelo.

BACKES, D. S.; BACKES, M. S.; ERDMANN, A. L.; BÜSCHER, A. O papel profissional do enfermeiro no Sistema Único de Saúde: da saúde comunitária à estratégia de saúde da família. Ciência \& Saúde Coletiva, v. 17, n. 1, p. 223-230, 2012.

BELANCIERI, M. F.; BELUCI, M. L.; SILVA, D. V. R.; GASPARELO, E. A. A resiliência em trabalhadores da área da enfermagem. Estudos de Psicologia (Campinas), v. 27, n. 2, p. 227-233, 2010.

CADONÁ, M. A.; GÓES, C. H. Juventude e trabalho: emprego e desemprego entre jovens no município de Santa Cruz do Sul (RS). Barbarói, n. 39, p. 36-52, 2013.

DAMÁSIO, B. F. Uso da análise fatorial exploratória em psicologia. Avaliação Psicológica, v. 11, n. 2, p. 213-228, 2012.

CHIAVENATO, I. Gestão de pessoas. Rio de Janeiro: Elsevier, 2004.

DRUCK, G. Trabalho, precarização e resistências: novos e velhos desafios? Caderno CRH, v. 24, n. spe. 1, p. 37-57, 2011.

ELIAS, M. A.; NAVARRO, V. L. A relação entre o trabalho, a saúde e as condições de vida: negatividade e positividade no trabalho das profissionais de enfermagem de um hospital escola. Revista Latino-Americana de Enfermagem, v. 14, n. 4, p. 517-525, 2006. 
FILIPPIM, E. S.; GEMELLI, I. M. P. Gestão de pessoas na Administração Pública: o desafio dos municípios. Revista de Administração, Contabilidade e Economia - RACE UNOESC, v. 9, n. 1, p. 153-180, 2010.

FONTANA, R. T.; LAUTERT, L. A situação de trabalho da enfermagem e os riscos ocupacionais na perspectiva da ergologia. Revista Latino-Americana de Enfermagem, v. 21, n. 6, p. 1306-1313, 2013.

\section{GEORGE, D.; MALLERY, P. SPSS for Windows step} by step: a simple guide and reference. 11.0 update. 4 . ed. Boston: Allyn \& Bacon, 2003.

HARMAN, H. Modern factor analysis. 2. ed. Chicago: The University of Chicago Press, 1967.

HIRATA, H. A precarização e a divisão internacional e sexual do trabalho. Sociologias, n. 21, p. 24-41, 2009.

HORA, K. P. H. S.; FERREIRA, M. G. L.; SILVA, A. P. F. Elementos desencadeadores do estresse no trabalho do enfermeiro hospitalar: uma revisão integrativa de literatura. Cadernos de Graduação - Ciências Biológicas e da Saúde, v. 1, n. 2, p. 167-180, 2013.

JAHODA, M. Empleo y desempleo: un análisis sociopsicológico. Madrid: Morata, 1982/1987.

LIMA, J. C. A terceirização e os trabalhadores: revisitando algumas questões. Cadernos de Psicologia Social do Trabalho, v. 13, n. 1, p. 17-26, 2010.

LIMA, R. V. M.; PEDRÃO, L. J.; GONÇALVES, J. G.; LUIS, M. A. V. Papéis, conflitos e gratificações do enfermeiro de serviços abertos de assistência psiquiátrica. Revista Eletrônica de Enfermagem, v. 12, n. 2, p. 348-353, 2010.

MACHADO, M. H.; VIEIRA, A. L. S.; OLIVEIRA, E. Construindo o perfil da enfermagem. Enfermagem em foco, v. 3, n. 3, p. 119-122, 2012.
MARQUES, A. P. P. Reestruturação produtiva e recomposições do trabalho e emprego: um périplo pelas "novas" formas de desigualdade social. Ciência e Saúde Coletiva, v. 18, n. 6, p. 1545-1554, 2013.

MENDONÇA, H.; TAMAYO, A. Percepção de justiça e reações retaliatórias nas organizações: análise empírica de um modelo atitudinal. Revista de Administração Contemporânea, v. 8, n. 2, p. 117 135, 2004.

MÉSZÁROS, I. Desemprego e precarização: um grande desafio para a esquerda. In: ANTUNES, R. (Org.). Riqueza e miséria do trabalho no Brasil. São Paulo: Boitempo, 2006. p. 27-44.

NAVARRO, V. L.; PADILHA, V. Dilemas do trabalho no capitalismo contemporâneo. Psicologia \& Sociedade, v. 19, n. spe., p. 14-20, 2007.

PADILHA, V. Qualidade de vida no trabalho num cenário de precarização: a panaceia delirante. Trabalho, Educação e Saúde, v. 7, n. 3, p. 549-563, 2009.

PASQUALI, L. Análise fatorial para pesquisadores. Brasília: LabPAM, 2012.

RAMALHO, J.; SANTANA, M. Trabalhadores, sindicatos e a nova questão social. In: RAMALHO, J.; SANTANA, M. (Orgs.). Além da fábrica: trabalhadores, sindicatos e a nova questão social. São Paulo: Boitempo, 2003. p. 11-43.

RODRIGUES, E. P.; RODRIGUES, U. S.; OLIVEIRA, L. M. M.; LAUDANO, R. C. S.; NASCIMENTO SOBRINHO, C. L. Prevalência de transtornos mentais comuns em trabalhadores de enfermagem em um hospital da Bahia. Revista Brasileira de Enfermagem, v. 67, n. 2, p. 296-301, 2014.

SCHMIDT, D. R. C.; DANTAS, R. A. S. Qualidade de vida no trabalho de profissionais de enfermagem, atuantes em unidades do bloco cirúrgico, sob a ótica da satisfação. Revista Latino-Americana de Enfermagem, v. 14, n. 1, p. 54-60, 2006. 
SILVA, N. M.; MUNIZ, H. P. Vivências de trabalhadores em contexto de precarização: um estudo de caso em serviço de emergência de hospital universitário. Estudos e Pesquisas em Psicologia, v. 11, n. 3, p. 821-840, 2011.

SKEVINGTON, S.; DAWKES, D. Minorities at work: men in a woman's world. In: CANTER, D.; JESUÍNO, J.; SOCZKA, L.; STEPHENSON, G (Orgs.). Environmental Social Psychology. Londres: Kluwer Academic Publishers, 1988. p. 272-280.

SOUZA, N. V. D. O.; SANTOS, D. M.; RAMOS, E. L.; ANUNCIAÇÃO, C. T.; THIENGO, P. C. S.; FERNANDES, M. C. Repercussões psicofísicas na saúde dos enfermeiros da adaptação e improvisação de materiais hospitalares. Escola Anna Nery, v. 14, n. 2, p. 236-243, 2010.

WISNIEWSKI, D.; SILVA, E. S.; ÉVORA, Y. D. M.; MATSUDA, L. M. The professional satisfaction of the nursing team vs. work conditions and relations: a relational study. Texto \& Contexto-Enfermagem, v. 24, n. 3 , p. $850-858,2015$. 